\title{
A TLC-bioassay based method for detection of fungicide residues on harvested fresh produce
}

\author{
H.M.C.K. Kanatiwela* and N.K.B. Adikaram \\ Department of Botany, Faculty od Science, University of Peradeniya, Peradeniya.
}

Revised: 06 May 2009 ; Accepted: 15 June 2009

\begin{abstract}
This paper reports the results of a study performed to investigate the potential of a thin layer chromatography (TLC) bioassay for detection of fungicidal residues on harvested fresh produce. A procedure for collection of fungicidal residues from the surface of fresh produce and detection using bioassay was developed. This method was subsequently applied successfully to detect and quantify fungicide residues in a commercial sample of tomato. The method is convenient, cost-effective, and sensitive enough for screening residues of known fungicides on fresh produce in laboratories with limited resources.
\end{abstract}

Key words: Fungicide residues, harvested produce, TLC bioassay.

\section{INTRODUCTION}

Pesticides play an important role in present day agriculture. Pest management in many countries is mostly pesticide dependent. Their residues may remain in or on agricultural produce and processed foods. Public concern over the pesticide residues has increased during the recent years due to their widespread use and the potential health hazards ${ }^{1}$. Therefore, pesticide residues in harvested fresh produce must be regularly monitored to ensure safety. Any method used to determine pesticide residues should enable to monitor their presence even at low levels.

Analysis of food for pesticide residues is a complex process and requires both sophisticated equipment and trained personnel. The currently used methods for detecting and quantifying pesticide residues include gas chromatography (GC), gas chromatography coupled with mass spectrometry (GC/MS) and high performance liquid chromatography (HPLC). Liquid chromatography and mass spectrometry are also used in pesticide analysis ${ }^{2}$. These methods are popular since they give accurate results. Immunological methods are also widely used in residue analysis for pesticides such as organochlorines, organophosphates, triazines, phenoxy acids among others in water, soil and food $^{3}$. These methods are rapid, sensitive, specific and relatively cost effective. The minimum limit of detection and quantification depends on the technique which is used as well as the interested pesticide. For example, in GC/ MS the limit of detection is $0.004 \mathrm{mg} / \mathrm{kg}$ and the limit of quantitative determination is $0.013 \mathrm{mg} / \mathrm{kg}^{4}$. The selection of the analytical method should depend on the necessary detection level.

Thin layer chromatography (TLC) is an alternative technique which can be used for detecting known pesticide residues or for confirmation of tentatively identified compounds ${ }^{6}$. It is easily carried out in any chemical laboratory. The procedure is simple, yet sensitive, precise, versatile, rapid and inexpensive. The method was widely used in 1960s and 70s for pesticide residue analysis, but lost its niche in the analytical field with the introduction of GC/MS and HPLC 5 . Various solvents or solvent combinations, adsorbents, thickness of the adsorbent, detection system and condition during separation can be used for quantitative and qualitative analysis of many compounds ${ }^{7}$. It can be used for the identification and quantitative determination of a large number of pesticides ${ }^{8}$. In addition, it is especially useful for the confirmation of compounds that cannot be detected with GC and HPLC/MS 9 .

The objective of the present study was to develop a convenient, yet sensitive enough method to detect fungicide residues on fresh agricultural produce in resource limited laboratories. TLC coupled with a

\footnotetext{
*Corresponding author (chamini81@yahoo.com)
} 
bioassay method was tested for its potential for detection of fungicide residues in vegetables cultivated in the Central Province.

\section{METHODS AND MATERIALS}

Three commercial fungicides, Captaf 50W (captan), Dithane M-45 (mancozeb) and Polyram M (maneb), which are commonly used as field sprays for vegetables in the Central Province, were considered for use as the test fungicides. The best solvent for each fungicide was determined using solvents with different polarities, The test solutions were prepared by adding $1 \mathrm{~mL}$ portions of dichloromethane, chloroform, methanol, ethyl acetate, water and dimthyl sulfoxide (DMSO) to $1 \mathrm{mg}$ quantities of the captan $(50 \% \mathrm{w} / \mathrm{w})$, Mancozeb $(80 \% \mathrm{w} / \mathrm{w})$ and maneb $(80 \% \mathrm{w} / \mathrm{w})$ and mixing.

A solution of captan was prepared by dissolving $1 \mathrm{mg}$ in $10 \mathrm{~mL}$ dichloromethane. Solutions of mancozeb and maneb were made in DMSO. Aliquots $(50 \mu \mathrm{L})$ of captan, mancozeb and maneb solutions were applied on to a TLC plate $(0.5 \mathrm{~mm}$ thick, silica gel, MERCK, USA) and the plate was developed in acetone:toluene $(1: 9 \mathrm{v} / \mathrm{v}){ }^{10}$. After air-drying, the plate was subjected to TLC bioassay ${ }^{11}$.

A 10 day old sporulating culture of Cadosporium cladosporioides grown on potato dextrose agar (PDA) medium was flooded with $20 \mathrm{~mL}$ of Czapek Dox nutrient solution and the mycelium was scraped to dislodge conidia. The thick conidia suspension prepared was filtered through glass wool. The TLC plates were carefully sprayed with the conidia suspension $\left(10^{6}\right.$ conidia $\left./ \mathrm{mL}\right)$ using an atomizer until the silica gel was thoroughly wet. The plate was immediately placed in a moisture chamber $\left(100 \% \mathrm{RH}\right.$ and $\left.26 \pm 2{ }^{\circ} \mathrm{C}\right)$ for incubation for $2-3 \mathrm{~d}$ until green mycelial growth was visible. Areas showing absence of mycelial growth were taken as inhibition zones.

Captan was selected as the test fungicide for the study as it was soluble in dichloromethane. The other two fungicides which were soluble only in non-volatile DMSO were not used for the study as DMSO is known to interfere with the TLC bioassay.

The presence of fungicide residues on fresh produce was detected by TLC bioassay. A $0.1 \%$ captan solution was prepared by dissolving $0.1 \mathrm{~g}$ in $100 \mathrm{~mL}$ of distilled water. Twenty fruits weighing about $1 \mathrm{~kg}$ of fungicidefree tomatoes obtained from a home garden in Peradeniya were sprayed with the captan solution using an atomizer. The fruits were kept for $3 \mathrm{~d}$ in the laboratory at $26 \pm 2^{\circ} \mathrm{C}$ and each fruit was successively washed in a $10 \mathrm{~mL}$ portion of $\mathrm{CH}_{2} \mathrm{Cl}_{2}$ by gently rubbing the surface of each fruit. The solvent in the washings was evaporated (at $40^{\circ} \mathrm{C}$ ) under reduced pressure using a rotary evaporator (Stuart RE300) and the residue was dissolved in $1 \mathrm{~mL}$ of $\mathrm{CH}_{2} \mathrm{Cl}_{2}$

Aliquots $(50 \mu \mathrm{L})$ were spotted ( $3-5 \mathrm{~mm}$ diameter) on freshly activated TLC plates $(0.5 \mathrm{~mm}$ thick, silica gel, MERCK, USA). The plates were developed in acetone: toluene $(1: 9 \mathrm{v} / \mathrm{v})^{10}$, air-dried overnight at room temperature $\left(26 \pm 2^{\circ} \mathrm{C}\right)$ and subjected to bioassay.

The same technique was used to determine the residual captan in tomatoes purchased commercially. Twenty tomato fruits weighing about $1 \mathrm{~kg}$ were obtained from a wholesale market in Kandy. Surface washings of fruits were obtained in $\mathrm{CH}_{2} \mathrm{Cl}_{2}$ as described previously. After evaporating the solvent, the residue was taken up in $1 \mathrm{~mL}$ of $\mathrm{CH}_{2} \mathrm{Cl}_{2}$. Aliquots, $50 \mu \mathrm{L}, 100 \mu \mathrm{L}$, and $200 \mu \mathrm{L}$, were applied on to a TLC plate. An aliquot $(10 \mu \mathrm{L})$ of a captan solution $(0.05 \mathrm{mg} / \mathrm{mL})$ was spotted on the TLC plate as the reference sample. Surface washing of untreated home-grown tomato $(1 \mathrm{~kg})$ was obtained and an aliquot $(200 \mu \mathrm{L})$ of the solution was spotted on the same TLC plate. The TLC plate was developed in acetone: toluene $(1: 9 \mathrm{v} / \mathrm{v}){ }^{10}$ and after air-drying overnight, the plate was subjected to the Cladosporium bioassay. The experiment was repeated.

The presence of captan in the surface washings was further established by co-chromatography with a $10 \mu \mathrm{L}$ aliquot of the commercial captan solution. Aliquots of (i) $50 \mu \mathrm{L}$ of the washing $+10 \mu \mathrm{L}$ of $\mathrm{CH}_{2} \mathrm{Cl}_{2}$, (ii) $50 \mu \mathrm{L}$ of the washing $+10 \mu \mathrm{L}$ of captan solution and (iii) $10 \mu \mathrm{L}$ of the captan solution $+50 \mu \mathrm{L}$ of $\mathrm{CH}_{2} \mathrm{Cl}_{2}$ were spotted on a TLC plate. The TLC plate was developed and subjected to bioassay as described previously.

The residual fungicide (captan) in tomato was quantified using the area of the inhibition zone produced on the TLC plate. A $0.05 \mathrm{mg} / \mathrm{mL}$ stock solution of captan was prepared in $\mathrm{CH}_{2} \mathrm{Cl}_{2}$. A series of dilutions containing $0.05 \mu \mathrm{g}-10 \mu \mathrm{g}$ of captan was prepared by diluting the stock solution with $\mathrm{CH}_{2} \mathrm{Cl}_{2}$. Aliquots $(100 \mu \mathrm{L})$ of different dilutions of captan containing $0.05,0.1,0.15,0.2,0.25$, $0.5,1.0,1.5,2.0,2.5 ., 5.0,7.5$ and $10.0 \mu \mathrm{g}$ of captan were spotted on a TLC plate. The plate was developed and subjected to the Cladosporium bioassay. The area of inhibition zones was measured and a calibration curve, captan concentration vs inhibition area, was drawn. The captan concentration in the surface washing of test samples was determined using the calibration curve. 


\section{RESULTS}

Captan was soluble in both dicholoromethane and chloroform and not completely soluble in water or DMSO. Both mancozeb and maneb were completely soluble only in DMSO. Maneb was slightly soluble in water too.

Captan $(0.002 \mathrm{mg})$ produced a large clear inhibition area on the TLC at retention factor Rf. 0.70. Mancozeb and maneb also gave large inhibition areas at the base, Rf. 0.00 (Figure 1).

The concentrated surface washings, taken from tomato fruits three days after spraying with captan, produced a clear inhibition zone on TLC at Rf. 0.70. The inhibition zone corresponding to the commercial captan solution was clear and large, closer to that of the surface washings, at Rf. 0.72 (Figure 2).

The surface washings of the tomato fruits purchased from the market on bioassay, produced three inhibition zones on the TLC plate suggesting the presence of three antifungal substances. The $\mathrm{Rf}$ value of the inhibition zone at Rf. 0.70 was similar to that of captan. The $\mathrm{Rf}$ values of the other two inhibition areas were 0.00 and 0.07 , suggesting the possibility of presence of other fungicide residues. The area of the antifungal zones increased with the increase of the volume of the washing spotted. The surface washings of the untreated home-grown tomato sample did not cause any inhibition of fungal growth on TLC bioassay (Figure 3).

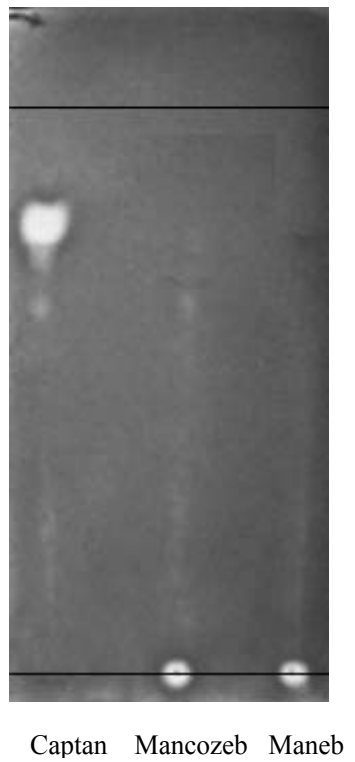

Figure 1: Inhibition areas on TLC spotted with pure fungicides and bioassayed with C. cladosporioides
When aliquots of surface washings of commercial tomato sample and pure captan were co-chromatographed, a larger antifungal area at an $\mathrm{Rf}$ value corresponding to captan was observed (Figure 4).

The area of the inhibition zone produced was plotted against the concentration of captan as a calibration curve for quantification of captan in test samples. The area of the inhibition zone increased with the increase of the amount of captan spotted (Figure 5).

There was a very good correlation $(\mathrm{y}=10.933 \mathrm{x}$ $+65.997, \mathrm{R}^{2}=0.9559$ ) between the amount of captan and the inhibition area (Figure 6a). A separate graph $\left(y=28.24 x+49.344, R^{2}=0.9742\right)$ was constructed for smaller amounts of captan, ranging from 0.5 to $1.5 \mu \mathrm{g}$, as small amounts could not be determined using the above graph (Figure 6b). The captan residues found in the test sample were quantified using the above graph and they ranged between $7.3-8.5 \mu \mathrm{g} / \mathrm{kg}$.

\section{DISCUSSION}

The TLC bioassay is adapted in this research to screen fungicide residues on harvested fresh produce, as an alternative for currently used sophisticated and expensive techniques. The $\mathrm{Rf}$ values of the fungicides selected for the study were determined by TLC bioassay. The presence of fungicide residues on the tomato fruit was demonstrated by first taking dichloromethane washings of the fruit and then bioassaying washings on a TLC plate.

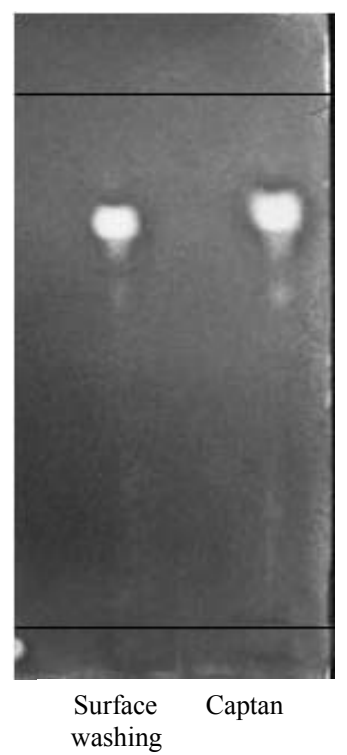

Figure 2: TLC bioassay of the surface washings, taken from tomato fruits sprayed with captan 


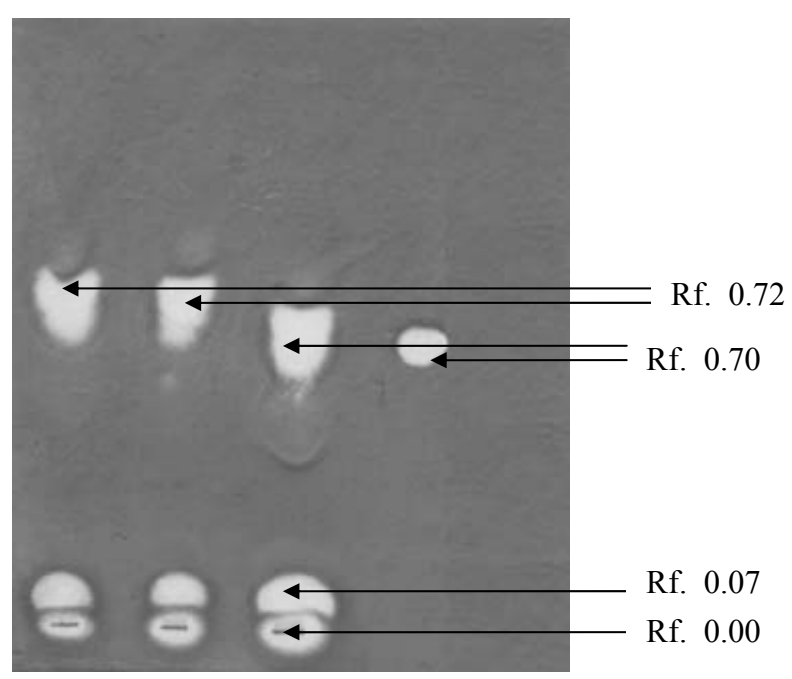

(a) (b)

(d)

(e)

Figure 3: TLC bioassay of concentrated surface washings of tomato purchased from the market (a) $50 \mu \mathrm{l}$, (b) $100 \mu \mathrm{l}$, (c) $200 \mu \mathrm{l}$, (d) captan and (e) surface washings of fungicide free tomato

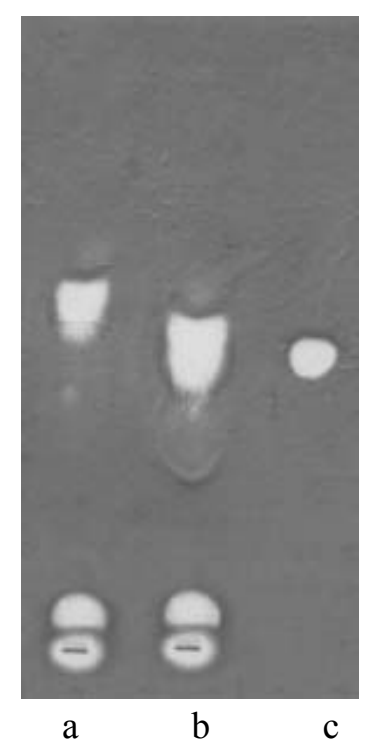

Figure 4: TLC bio-assay of (a) surface washings of tomato fruits, (b) surface washings + captan and (c) a reference sample of the fungicide captan

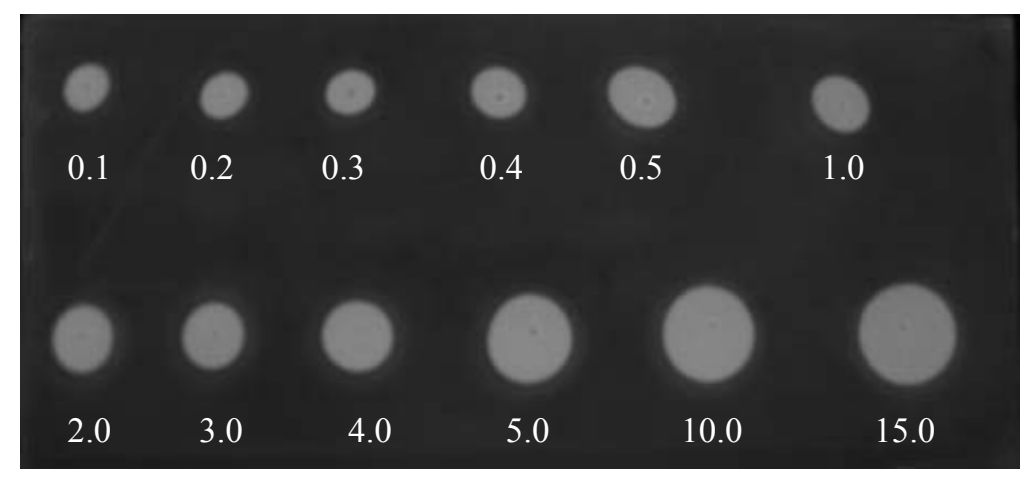

Figure 5: TLC-bioassay of different quantities $(\mu \mathrm{g})$ of captan

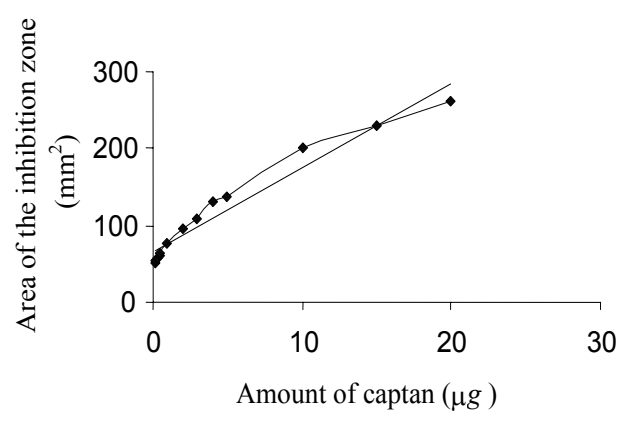

Figure 6a: Regression curve, the area of the inhibition vs the amount of captan

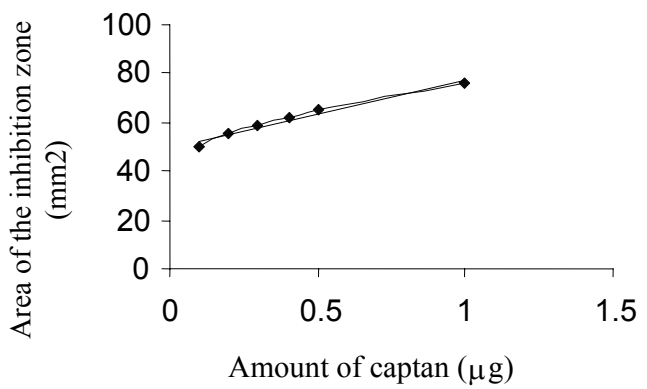

Figure 6b: Regression curve for captan at concentrations below $1 \mu \mathrm{g}$. 
The Rf value of captan was successfully determined for the solvent system acetone: toluene $(1: 9 \mathrm{v} / \mathrm{v}){ }^{10}$ which ranged between 0.7-0.72. Both mancozeb and maneb were retained on the base in the above solvent system and could not therefore be distinguished from each other. Previous studies have shown that the optimum conditions for reproducibility and detection sensitivity, which are essential in residue analysis, were obtained on a TLC plate in the Rf range of 0.2-0.7. Therefore, this solvent system is suitable for detection of captan but not for the other two.

Tomatoes purchased from the market were analysed for captan residues, and most of the samples contained residues of more than one fungicide. The spot with the Rf value of 0.7 was identified as residual captan. The presence of captan on the fruit peel was confirmed by performing co-chromatography. An enlarged, single inhibition zone, corresponding to captan was obtained, when the concentrated washing was chromatographed with captan indicating that both have the same $\mathrm{Rf}$ value. The presence of more than one inhibition zone on the TLC plate may be due to the treatment of crops with more than one fungicide during its cropping season and/ or after harvesting or due to decomposed products of the fungicides used.

In TLC bioassay, the fungal spore inhibition was used as an indication of fungicidal activity. It detects only the fungicides that are at a certain concentration level ${ }^{9}$. The sensitivity of the fungi towards the fungicide may vary. Hence the bioassay can be performed using different species of fungi as the bioassay agent, for example, Fusarium spp. Aspergillus spp. Penicillium spp., Trichoderma viride, Botrytis cinerea and Alternaria spp. ${ }^{5,12}$. The test fungi should be selected depending on the required sensitivity as well as the objective. Mancozeb and maneb were completely soluble in DMSO, but such non-volatile solvents could remain on silica gel and interfere with the detection methods preventing the fungal spore germination $^{13}$. Therefore, alternate detection method may be used to determine the presence of polar fungicide residues.

The calibration curve constructed for quantification captan residues showed a good correlation between the quantity of captan and the area of the inhibition zone. It has been found that the reproducibility and the detection sensitivity are optimum when the sample spot is in 3-4 mm diameter at $2 \mathrm{~cm}$ from the edge of the plate ${ }^{5}$. Therefore, it is essential to construct separate calibration curves under each laboratory condition and the range of concentration of fungicide to be analysed. For captan it is suitable to use two different curves, one for smaller quantities $(<1 \mu \mathrm{g})$ and another for larger quantities $(>1 \mu \mathrm{g})$. The TLC scanner was to quantify the pesticide residues on the TLC plate and the calibration curve was linear in the range $8-24 \mu \mathrm{g}^{6}$.

The accuracy of the method can be improved by purifying the extract using gel permeation chromatography (GPC) before they are used in $\mathrm{TLC}^{14}$. Though the TLC technique is considered simple, it has been found that the results obtained from gas chromatography and TLC are same, both have nearly similar detection ability ${ }^{15}$.

There are certain limitations associated with this technique. Any antifungal compound present naturally in the skin can interfere with the results, because in this technique the presence of substances toxic to Cladosporium is indicated by the lack of aerial mycelium $^{11}$. This can be overcome by purifying the extracts and maintaining a negative control (i.e. a sample of extraction without any fungicidal treatment). The latter can be run together with the rest of the samples. Futher, this method is difficult to be applied for high polar fungicides like mancozeb and maneb.

This method can be developed for screening any fungicide by changing the solvent system and bioassay organism. The method can also be applicable for any commodity treated with fungicides.

\section{References}

1. Sumith J.A (2005). Food and Agriculture Organization (FAO) Corporate Document, Repository, Sri Lanka.

2. Carvajal L.G., Loewy R.M. \& de D'angeló P. (2005).Use of multi-residue extraction associated with TLC separation and biological detection in fruit and tomato. Validation of Thin-layer Chromatographic Methods for Pesticide Residue Analysis. Results of the Coordinated Research Projects Organized by the Joint FAO/IAEA Division of Nuclear Techniques in Food and Agriculture. International Atomic Energy Authority (IAEA), pp. 123-149.

3. Razak C.N.A., Salam F., Ampon K., Basri M. \& Salleh A.B. (1998). Development of ELISA for detection Parathion, Carbofuran, and 2,4-Diclorophenoxyacetic acid in water, soil, vegetables and fruits. Annals of the New York Academy of Sciences 864: 479.

4. Cesnik H.B. \& Gregorcic A. (2006). Validation of the method for the determination of dithiocarbamates and thiuram disulphide on apple, lettuce, potato, strawberry and tomato matrix. Acta Chimica Slovenica 53(1):100-104.

5. Sherma J. (2005). Review of advances in the thin layer chromatography. Journal of Environmental Science and Health 42(4): 429-449. 
6. Ambrus A., Füzesi I., Lantos J., Korsos I., Szathmáry M., Hatfaludi T. \& Rathor N. (2005). Application of TLC for confirmation and screening of pesticide residues in fruits, vegetables and cereal grains: repeatability and reproducibility of Rf and MDQ values. Validation of Thin-layer Chromatographic Methods for Pesticide Residue Analysis. Results of the coordinated research projects organized by the Joint FAO/IAEA Division of Nuclear Techniques in Food and Agriculture, International Atomic Energy Authority (IAEA) pp. 71-123.

7. Mandoza C.E. (1973). Thin layer chromatography. Journal of Chromatography 78: 29-40.

8. Ugbeye G.U., Denloye S., Oloko D., Okafor R., Fadahusi G., Gbadebo F., Ilori D. \& Adisa S.O. (2003). Development and validation of thin layer chromatographic screening methods for pesticide. www.foodafrica.nri.org/safety/ safetypapers/Nafdacos2.doc Accessed in March 2007.

9. Ambrus A., Fuzesi I., Susan M., Dobi D., Lantos J., Zakar F. \& Korsos A. (2005). A cost effective screening method for pesticide residue analysis in fruits, vegetables. Journal of Environmental Science and Health 40(2): 297-339.

10. Hamilton D.J. \& Simpson B.W. (1969) Thin Layer Chromatography. Journal of Chromatography 39:186194.
11. Klarman W.L. \& Stanford J.B. (1968). Isolation and purification of an antifungal principle from infected soy beans. Life Science 7:1095-1103.

12. Balinova A. (1995). Extension of the bioautograph technique for multiresidue determination of fungicide residues in plants and water. Analytica Chimica Acta 311(3): 423-427.

13. Bui V.T., Ahad E., Rheaume D. \& Whitehead R. (1997). Evaluation of branched glycidyl azide polymer purified by solvent extraction. Industrial and Engineering Chemistry Research 36 (6): 2219 -2224.

14. Qian C. \& Liu D. \& Kong X. (2005). Determination of organophosphorus pesticides in grain by TLC. Validation of Thin-layer Chromatographic Methods for Pesticide Residue Analysis, Results of the Coordinated Research Projects Organized by the Joint FAO/IAEA Division of Nuclear Techniques in Food and Agriculture, pp. 117192.

15. Liu D. \& Qian C. (2005). Comparison of thin layer and gas chromatographic methods for the determination of herbicide residues in grain and soil. Validation of ThinLayer Chromatographic Methods for Pesticide Residue Analysis, Results of the Coordinated Research Projects Organized by the Joint FAO/IAEA Division of Nuclear Techniques in Food and Agriculture pp. 175-181. (IAEA). 